\title{
LA NATURALEZA ALADA EN EL LENGUAJE PICTÓRICO ${ }^{1}$
}

\author{
María de Lourdes Navarijo Ornelas \\ Instituto de Biología, UNAM
}

\section{Introducción}

Desde su aparición en la faz de la tierra el hombre ha estado inevitable y necesariamente supeditado a su medio circundante. En consecuencia, con el paso del tiempo se han establecido relaciones de carácter material que le han permitido satisfacer la gran mayoría de sus necesidades cotidianas. A la vez, tanto flora como fauna han estado presentes de manera significativa en el pensamiento, normando las posiciones filosóficas y religiosas.

Las manifestaciones culturales de los pueblos mayas son un buen ejemplo de este vínculo ancestral. Esto se debe a los variados modos en que percibieron, aprendieron y procedieron ante la naturaleza para construir sus relaciones y alcanzar los altos niveles de desarrollo cultural, científico y tecnológico conocidos, pues es un hecho el florecimiento de sistemas calendáricos, cronológicos y astronómicos sumamente precisos, así como la creación de una escritura jeroglífica impar. En este tipo de acontecimientos tuvieron que participar forzosamente grandes conocimientos acerca de la naturaleza.

Sin embargo, cabe señalar que los estudios sobre la cultura maya se han enfocado de manera tradicional a los aspectos arqueológicos, religiosos, iconográficos, linguíísticos, estilísticos, etc., dejando casi siempre de lado los relacionados con la fauna. De esta coyuntura nace el interés de este estudio, porque de modo particular los conocimientos sobre las aves no han sido documentados, teniendo que las referencias sobre la fauna y, por ende, sobre las aves, existen sólo en función de los avances en otro género de investigación, como los estudios explicativos sobre los códices, las interpretaciones sobre las cualidades y funciones de las deidades y otros más.

Al respecto, una referencia concreta es el estudio de De la Garza (1995), quien se ha ocupado de revisar e interpretar las tan variadas y complejas significaciones religiosas de unas 18 especies de aves vinculadas con el dios supremo, con el Sol, con el lado nocturno de la vida y con el hombre mismo.

\footnotetext{
${ }^{1}$ En estas páginas deseo dejar constancia de mi reconocimiento a la doctora Beatriz de la Fuente, por haberme dado la oportunidad de participar en el proyecto "La pintura mural prehispánica en México", así como a todos mis compañeros, de quienes he aprendido tras nutridas discusiones.
} 


\section{Objetivo}

En razón de que las pruebas acerca de la magnitud de ideas y de conocimientos que sobre su entorno poseyeron y acumularon los mayas se encuentran dispersas en un buena cantidad de contextos, es propósito de este estudio dar cuenta de la importancia que tiene la existencia de una diversidad de especies de aves que participan en una expresión cultural particular: la pintura mural.

Esta diversidad de especies autoriza sugerir la existencia de un código de selección de aves, así como proponer argumentos que demuestran que su presencia tuvo un papel relevante en la cosmovisión, en donde converge la importancia del medio natural enlazada a sus percepciones, usos y saberes.

\section{Marco de referencia}

La importancia de las aves en el mundo maya se puede observar por medio de diversas evidencias, como lo son las variadas representaciones en los códices, debido a que en ellos se han reconocido alrededor de una docena de especies, como el pelícano, varias formas de garzas, águilas, codornices, guacamayas, trogones y el quetzal, teniendo que las aves se encuentran asociadas a rituales o enlazadas con una deidad en forma particular.

Igualmente, la riqueza de formas animales utilizadas en diversos diseños cerámicos es exponente de la curiosidad que despertó la fauna (Navarijo, 1999), así como las diversas representaciones en la arquitectura de diferentes sitios arqueológicos.

Hallar a las aves en la composición de numerosos topónimos es otro testimonio probatorio, sobre todo porque éstos contienen valiosa información del medio y del hombre mismo. También existen referencias sobre la manera conceptual en que las aves estuvieron asociadas con el nombre de linajes, o bien se les puede encontrar como componentes de glifos nominales en las inscripciones del Clásico.

De igual forma, diferentes aves son instrumentos protagónicos en los textos que nos han llegado y constituyen excelentes evidencias del interés hacia sus características y cualidades. Así, en diversos pasajes del Popol Vuh, se advierte que los rasgos físicos y los patrones de conducta fueron observados, valorados y posteriormente culturizados, como la facultad de volar que es expresada de manera poética:

tú, pájaro, vivirás en los árboles y volarás por los aires, alcanzarás la región de las nubes, rozarás la transparencia del cielo y no tendrás miedo de caer [...] y los pájaros hicieron, entre los ramajes sus nidos (Popol Vuh, 1985: 21).

Por su voz y su canto, las aves fueron elegidas para intervenir como eficientes mensajeras; así el gavilán, la cotorra, el loro, el búho y el cuervo son porta- 
dores de noticias en la narración. De igual forma, como mensajeras del Sol varias aves se mencionan en los Cantares de Dzitbalché (Barrera, 1992).

\section{Resultados y discusión}

A este breve conjunto de evidencias se suman las muestras de pintura mural localizadas en seis sitios arqueológicos del área maya, que corresponden a períodos y estilos diferentes. Los sitios considerados en este estudio son Calakmul y Xuelén en Campeche, Bonampak en Chiapas, Xelhá en Quintana Roo y las pinturas de Mulchic y Chichén Itzá en Yucatán. ${ }^{2}$

El análisis de estas imágenes confirma la calidad de conocimientos biológicos y ecológicos que poseían los mayas, de acuerdo con el detalle y fidelidad con que fueron captados los rasgos más característicos y particulares que posibilitan reconocer la identidad taxonómica de las especies representadas en cada caso. Sobre este punto se debe tener en consideración que la imagen caracterizada es una forma singular de expresar una idea, un conocimiento, dado que existe una estrecha relación entre lo que se ve, se dibuja y se sabe.

Una vez reconocida la apariencia e identidad de un ave, ¿qué importancia adquiere dicha presencia en el discurso pictórico? Para dar una respuesta satisfactoria son juzgados los siguientes tres puntos que delimitan el universo avifaunístico: a) formas de presencia, b) riqueza específica y, por último, c) el cometido simbólico de las especies de aves representadas. Estos análisis apoyan en diferente medida los estudios iconográficos.

\section{Presencias}

En términos generales, las aves que han sido estudiadas en los distintos sitios arqueológicos fueron representadas con el cuerpo parcial (sólo la cabeza, o la cabeza y patas, o en posición $3 / 4$ ), o bien se les ve con el cuerpo completo, por lo que para su estudio sistemático he reconocido tres modalidades básicas en la representación pictórica, contando con una posible cuarta para reunir a los fragmentos no determinados (Navarijo, 2000).

Por sus características las aves representadas en la pintura mural maya quedan incluidas en dos de las tres modalidades propuestas, esto es:

1) Cuando en una escena se observa un solo individuo, corresponde obviamente a una sola especie de ave. Los ejemplos son: la garza completa que figura en la escena conocida como "Aldea maya a orillas del mar", en el

${ }^{2}$ Los análisis ornitológicos pormenorizados de los murales han sido publicados en la obra $\mathrm{La}$ pintura mural prehispánica en México, coordinada por Beatriz de la Fuente, 1998 y 2001, excepto lo referente al sitio de Calakmul. 
Templo de los Guerreros en Chichén Itzá; el Milano cola blanca dibujado en la zona basal del lado norte del mismo Templo de los Guerreros y, por último, el colibrí que fuera parte de un tocado, que se conserva en un fragmento procedente del sitio de Mulchic, en el Palacio Cantón de Mérida.

2) En la escena se distinguen varios individuos de aves que pertenecen a diferentes especies. Los casos ilustrativos son: los cuatro loros y 14 guacamayas rojas del mural 1 "Los Pájaros" en Xelhá, Quintana Roo; tres especies y cuatro individuos en Calakmul, ${ }^{3}$ Campeche, y, se cuenta con cinco especies, con por lo menos 16 individuos, pintados en la estructura 1 de Xuelén, situado también en Campeche.

En cuanto a los niveles de integración temática identificados (Navarijo: op. cit.), las aves están presentes en la pintura como individuos y son elementos significativos en la escena, o bien son el tema central. No obstante, la presencia de las aves asimismo puede ser reconocida por medio de las plumas que fueron utilizadas en la confección de la vestimenta, en los diferentes adornos y en los tocados, como son aquellos que portan varios personajes plasmados en Bonampak.

Es importante advertir que en la manufactura de la vestimenta y de los diversos tocados que se distinguen en los murales y en la cerámica, fueron trabajadas desde una sola pluma hasta una cantidad considerable. Estas plumas proceden de varias especies de aves, lo que equivale a una presencia de la cual también se puede dar cuenta, aun cuando no se tenga la imagen del ave de manera formal.

\section{Riqueza específica}

El examen de la pintura mural maya determinó la representación de 44 individuos de aves que corresponden a la presencia de 16 especies. De igual forma, se cuenta con unas 16 especies reconocidas como parte de los materiales utilizados para elaborar diferentes tocados y adornos que portan algunos personajes de Bonampak, lo que en suma hace un total de 17 familias y 11 órdenes de aves presentes (cuadro 1 y 2). En este conteo de especies se dejaron de lado aquellos diseños que hoy día, lamentablemente, se encuentran muy deteriorados e incompletos, como algunos que se localizan en Xuelén, lo que impide que puedan ser identificados de un modo taxonómico confiable.

Para valorar el alcance de la presencia y representatividad de los grupos de aves reconocidos en la pintura mural, es menester señalar que la avifauna en la república mexicana es muy diversa y ocupa a nivel mundial el onceavo lugar al sumar unas 1076 especies reunidas en 88 familias y 22 órdenes. De estos 22 órdenes registrados, el de los Passeriformes (pájaros) es el mejor representado,

\footnotetext{
2003.

${ }^{3}$ Arqueólogo Ramón Carrasco Vargas, director del proyecto Calakmul, comunicación personal,
} 
Cuadro 1

ESPECIES DE AVES EN LA PINTURA MURAL MAYA

\begin{tabular}{|c|c|c|}
\hline orden/familia/especie & nombre común & sitio arqueológico \\
\hline \multicolumn{3}{|l|}{ Pelecaniformes } \\
\hline \multicolumn{3}{|l|}{ Pelecanidae } \\
\hline Pelecanus occidentalis & Pelícano café & Xuelén, Campeche \\
\hline \multicolumn{3}{|l|}{ Phalacrocoracidae } \\
\hline $\begin{array}{l}\text { Phalacrocoracidae brasilianus } \\
\text { Anhingidae }\end{array}$ & \\
\hline Anhinga anhinga & Anhinga americana & Xuelén, Campeche \\
\hline \multicolumn{3}{|l|}{ Ciconiiformes } \\
\hline \multicolumn{3}{|l|}{ Ardeidae } \\
\hline Ardea herodias & Garza morena & $\begin{array}{l}\text { Bonampak, Chiapas } \\
\text { Chichén Itzá, Yucatán }\end{array}$ \\
\hline \multicolumn{3}{|l|}{ Threskiornithidae } \\
\hline Ajaia ajaja & Espátula rosada & Calakmul, Campeche \\
\hline \multicolumn{3}{|l|}{ Cathartidae } \\
\hline Coragyps atratus & Zopilote negro & Xuelén, Campeche \\
\hline \multicolumn{3}{|l|}{ Anseriformes } \\
\hline Dendrocygna autumnalis & Pijije & Calakmul, Campeche \\
\hline \multicolumn{3}{|l|}{ Falconiformes } \\
\hline \multicolumn{3}{|l|}{ Accipitridae } \\
\hline Pandion haliaetus & Águila pescadora & Xuelén, Campeche \\
\hline Elanus leucurus & Milano cola blanca & Chichén Itzá, Yucatán \\
\hline \multicolumn{3}{|l|}{ Psittaciformes } \\
\hline \multicolumn{3}{|l|}{ Psittacidae } \\
\hline Ara macao & Guacamaya roja & Xelhá, Quintan Roo \\
\hline Amazona albifrons o & Loro frente blanca & Xelhá y Calakmul (?) \\
\hline Amazona xantholora & Loro yucateco & Xelhá y Calakmul (?) \\
\hline \multicolumn{3}{|l|}{ Apodiformes } \\
\hline \multicolumn{3}{|l|}{ Trochilidae } \\
\hline Phaethornis longuemareus o & Ermitaño enano & Mulchic, Yucatán \\
\hline Chlorostilbon canivetii & Esmeralda tijera & Mulchic, Yucatán \\
\hline
\end{tabular}




\begin{tabular}{|lll|}
\hline orden/familia/especie & nombre común & sitio arqueológico \\
\hline $\begin{array}{l}\text { Coraciiformes } \\
\text { Alcedinidae } \\
\text { Chloroceryle americana }\end{array}$ & Martín pescador & Chichén Itzá, Yucatán \\
$\begin{array}{l}\text { Passeriformes } \\
\text { Traupidae } \\
\text { Chlorophonia occipitalis } \\
\text { Cardinalidae } \\
\text { Guiraca caerulea }\end{array}$ & Clorofonia corona & Chichén Itzá, Yucatán \\
\hline
\end{tabular}

Cuadro 2

ESPECIES DE AVES EN LA PINTURA MURAL MAYA (PLUMAS)

\begin{tabular}{|ll|}
\hline orden/familia/especie & nombre común \\
\hline $\begin{array}{l}\text { Ciconiiformes } \\
\text { Ardeidae } \\
\text { Ardea herodias }\end{array}$ & \\
Galliformes & Garza morena \\
Phasianidae & \\
Meleagris ocellata & \\
Psittaciformes & Pavo ocelado \\
Psittacidae & \\
Ara militaris & \\
Ara macao & \\
Pionopsitta haematotis & \\
Pionus senilis & Guacamaya verde o militar \\
Amazona albifrons & Guacamaya roja \\
Amazona xantholora & Loro cabeza oscura \\
Amazona autumnalis & Loro corona blanca \\
Amazona farinosa & Loro frente blanca \\
Trogoniformes & Loro yucateco \\
Trogonidae & Loro cara amarilla \\
Pharomachrus mocinno & Loro corona azul \\
Piciformes & \\
Rhamphastidae & \\
Aulacorhynchus prasinus & Quetzal \\
& \\
\hline & \\
& \\
& \\
&
\end{tabular}




\begin{tabular}{|ll|}
\hline orden/familia/especie & nombre común \\
\hline $\begin{array}{l}\text { Passeriformes } \\
\text { Traupidae }\end{array}$ & \\
Piranga rubra & Tangara roja \\
Icteridae & \\
Cacicus melanicterus & Cacique mexicano o Tordo aliamarillo \\
Psacolius wagleri & Oropéndola o Zacua cabeza castaña \\
Psarocolius montezuma & Oropéndola Moctezuma \\
\hline
\end{tabular}

con 36 familias y más de 500 especies, seguido por el de los Charadriiformes (aves marinas como los chorlos, playeros, gaviotas y charranes) con ocho familias y 98 especies; mientras que el de los Apodiformes (vencejos y colibríes) agrupa sólo dos familias con 71 especies, y también el de los Falconiformes (gavilanes, águilas, halcones) se compone de dos familias, pero con 52 especies de rapaces diurnas.

Sin duda esta diversidad biológica se puede apreciar a lo largo y ancho de los $141523 \mathrm{~km}^{2}$ con que cuenta la península de Yucatán, en donde todavía prosperan 20 tipos diferentes de vegetación (Flores-Villela y Gerez, 1988). Por tanto, para cumplir con el propósito de determinar sí la presencia de aves es significativa o no, será suficiente una breve revisión referenciada de algunos de los órdenes reconocidos con el correspondiente número de familias incluidas y las especies detectadas como individuos, así como a través de las plumas, lo que en conjunto constituye una prueba concluyente de la diversidad y riqueza de especies utilizadas en la pintura mural (cuadro 3).

CuAdro 3

Presencia y RePRESENTATIVIDAD DE GRUPOS DE AVES

\begin{tabular}{|lcccc|}
\hline orden & núm. familias & $\%$ & núm. especies & núm. esp. plumas \\
\hline Pelecaniformes & 3 de 6 & 50 & 3 & 0 \\
Ciconiiformes & 3 de 4 & 75 & 3 & 1 \\
Anseriformes & 1 de 1 & 100 & 1 & 0 \\
Falconiformes & 1 de 2 & 50 & 2 & 0 \\
Galliformes & 1 de 3 & 33.3 & 0 & 1 \\
Psittaciformes & 1 de 1 & 100 & 3 & $7(+$ o -$)$ \\
Apodiformes & 1 de 2 & 50 & 1 & 0 \\
Trogoniformes & 1 de 1 & 100 & 0 & 1 \\
Coraciiformes & 1 de 2 & 50 & 1 & 0 \\
Piciformes & 1 de 4 & 25 & 0 & 1 \\
Passeriformes & 3 de 36 & 8.3 & 2 & 4 \\
\hline 11 ÓRDENES (52.4\%) & 17 FAMILIAS & \multicolumn{5}{c}{16 ESPECIES } \\
\hline
\end{tabular}


Lo que destaca primero en este registro es que de los 22 órdenes de aves que se distribuyen en la república mexicana, 21 ocurren en la península de Yucatán, teniendo la presencia de 11 en la pintura mural, esto es, $52.4 \%$. Este porcentaje ciertamente es demostrativo, sobre todo sí se considera que el número de especies que integran una familia varía, es decir, no es uniforme, al igual que el número de familias que conforman un orden.

La distribución de las aves en México tampoco es un evento homogéneo. Esto se debe a la conjugación de varios factores, como lo es la ubicación geográfica del territorio nacional, su historia geológica, la heterogeneidad topográfica y climática y, en consecuencia, la diversidad de ambientes, que albergan una gran riqueza de flora y de fauna sin par. En otras palabras, esto quiere decir que hay ausencias a nivel de especie, de familia y de orden en determinados lugares o regiones del país. Por ejemplo, el grupo de los colimbos con sus cuatro especies marinas está por completo ausente en la península, pues se distribuyen sólo en las costas del Pacífico. Por el contrario, tres órdenes alcanzan $100 \%$ de representatividad en el rubro de familia, y tres de las cuatro familias que integran el orden Ciconiiformes están representadas en la pintura mural por medio de la Garza morena, la Espátula rosada y el Zopilote común (cuadro 3).

El sentido exacto de la riqueza específica y representatividad también se puede apreciar a través de un solo grupo, como el de los Pelecaniformes (cuadro 4). Éste está formado por seis familias con 10 especies en la península; sin embargo, sólo tres de estas familias figuran en la pintura mural, con tres especies en total (17.65\%), el Pelícano café, el Cormorán oliváceo y la Anhinga americana. Entre estas familias, la Anhingidae incluye una sola especie (Anhinga anhinga), situación que hace que alcance $100 \%$ de representatividad.

La condición de las guacamayas y loros, reunidos en el orden Psittaciformes, es de una sola familia con 22 especies, de las cuales 17 ocurren en la península y de ellas se distinguen en la pintura mural tres especies como individuos, mien-

Cuadro 4

Presencia y Representatividad de los Pelecaniformes

\begin{tabular}{|lcccr|}
\hline familia & México & p. Yucatán & p. mural & $\%$ \\
\hline Phaethontidae & 3 esp. & 1 esp. & no & 0 \\
Sulidae & 5 esp. & 3 esp. & no & 0 \\
Pelecanidae & 2 esp. & 2 esp. & 1 esp. & 50 \\
Phalacrocoracidae & 4 esp. & 2 esp. & 1 esp. & 50 \\
Anhingidae & 1 esp. & 1 esp. & 1 esp. & 100 \\
Fregatidae & 2 esp. & 1 esp. & no & 0 \\
\hline 6 FAmILIAS & 17 ESP. & 10 ESP. & 3 ESP. \\
\hline
\end{tabular}


tras que unas ocho especies están representadas en las diferentes muestras de arte plumaria.

Ahora bien, ¿qué significado poseen estas relaciones citadas en términos de biodiversidad? De un modo un tanto simplista se puede decir que a mayor riqueza de especies en una región, mayor será el número de elementos visibles y por tanto iconográficos disponibles. Al mismo tiempo, la presencia de estas especies en la pintura mural (cuadros 1 y 2 ) a su vez es indicadora de los siguientes aspectos de interés:

1) Las especies reconocidas en la pintura mural son exponentes de la existencia de conocimientos amplios y precisos sobre el ambiente, los que permitieron a los mayas contar con diversas opciones para la selección de las especies más adecuadas para el lenguaje pictórico, además de reflejar el uso minucioso de diferentes especies como proveedoras de plumas para los trabajos de plumaria.

2) Se pone en evidencia la coexistencia de una tecnología para el buen logro en la caza selectiva y el transporte de cada una de las especies utilizadas, en particular para las labores de plumaria, a la vez que,

3) La presencia de ciertas aves también confirma el manejo de información definida sobre diversos aspectos de la conducta de las especies para su inclusión en el discurso pictórico, esto tras un proceso continuo de observación, asociación y valoración simbólica.

Los censos señalados aquí expresan por sí solos la importancia de la diversidad de especies en la pintura mural. Sin embargo, el complemento necesario es el examen del conjunto de características físicas y conductuales para contar con otros elementos definitorios sobre los criterios para elegir a las especies. Para este fin se procedió a revisar las características físicas más distintivas de cada una de las 16 especies reconocidas como individuos, como son la talla y el color en tanto parámetros particularmente conspicuos.

TALLA: el rango abarca de $9 \mathrm{~cm}$ a $163 \mathrm{~cm}$, situándose el colibrí y el Águila pescadora en las posiciones extremas. Este rango se dividió en cuatro intervalos de $40.75 \mathrm{~cm}$ para ubicar con mejor exactitud a las 16 especies, siendo el promedio $66.94 \mathrm{~cm}$, con el siguiente resultado basado en las medidas estándares y en los promedios para cada una de las especies (cuadro 5) (Peterson y Chalif, 1989; Howell y Webb, 1995):

1. Pequeño $(9$ a $39 \mathrm{~cm}$ ) con dos sub-intervalos: de 9 a $20 \mathrm{~cm}$ y de 27 a $39 \mathrm{~cm}$ reúne desde los colibríes y el Martín pescador hasta los dos loros y el Milano. En total son siete especies de tamaño pequeño.

2. Mediano regular (48 a $75 \mathrm{~cm}$ ): comprende al Pijije, el Cormorán y la Espátula rosada, donde la talla del cormorán es la promedio $(63.5$ a $68.5=66 \mathrm{~cm})$.

3. Mediano grande $(89$ a $115 \mathrm{~cm})$ : incluye a la Anhinga americana, la Guacamaya roja y a la Garza morena.

4. Grande (125 a $163 \mathrm{~cm}$ ): reúne al Pelícano café, al Zopilote negro y al Águila pescadora. 


\begin{tabular}{|c|c|c|}
\hline orden / especie & talla $(\mathrm{cm})$ & forma y color \\
\hline \multicolumn{3}{|l|}{ Pelecaniformes } \\
\hline Pelícano café & $112-137$ & $\begin{array}{l}\text { cuerpo robusto; pico largo, plano; bu- } \\
\text { che grande; dorso gris plateado, cuello } \\
\text { largo café y una raya lateral blanca. }\end{array}$ \\
\hline Cormorán oliváceo & $63.5-68.5$ & $\begin{array}{l}\text { pico delgado y aserrado en la punta: } \\
\text { cuello largo, negro grisáceo arriba; cara } \\
\text { con piel desnuda amarillenta marginada } \\
\text { con plumas blancas. }\end{array}$ \\
\hline Anhinga americana & $84-94$ & $\begin{array}{l}\text { esbelta, cola larga; pico muy afilado, } \\
\text { agudo; cuello largo y flexible; negruzca } \\
\text { con manchas grandes argénteas en las } \\
\text { partes delanteras de las alas. }\end{array}$ \\
\hline \multicolumn{3}{|l|}{ Ciconiiformes } \\
\hline Garza morena & $102-127$ & $\begin{array}{l}\text { cuello y patas largas, pico como lanza, } \\
\text { gris azulado; una raya blanca a lo largo } \\
\text { del cuello; vientre negruzco con muslos } \\
\text { canela; hombros negros. }\end{array}$ \\
\hline Espátula rosada & $71-79$ & $\begin{array}{l}\text { cabeza desnuda; pico ancho, muy apla- } \\
\text { nado; cuello, parte del pecho y espalda } \\
\text { blancos; alas y pecho rosa brillante; patas } \\
\text { largas. }\end{array}$ \\
\hline Zopilote negro & $140-158$ & $\begin{array}{l}\text { cabeza y cuello desnudos color gris; } \\
\text { plumaje negro sucio; punta de alas } \\
\text { blanquizcas; cola corta. }\end{array}$ \\
\hline \multicolumn{3}{|l|}{ Anseriformes } \\
\hline Pijije & $45.5-50.5$ & $\begin{array}{l}\text { cabeza grisáceo; cuello largo, pico pla- } \\
\text { no rojizo; plumaje rojizo con vientre } \\
\text { negro; en las alas, una mancha blanquiz- } \\
\text { ca lateral. }\end{array}$ \\
\hline \multicolumn{3}{|l|}{ Falconiformes } \\
\hline Águila pescadora & $153-173$ & $\begin{array}{l}\text { cabeza y partes inferiores blancas; un } \\
\text { antifaz oscuro; pico corto ganchudo; } \\
\text { arriba café oscuro; patas grises. }\end{array}$ \\
\hline Milano cola blanca & $38-40.5$ & $\begin{array}{l}\text { cabeza blanca; dorso gris pálido, vien- } \\
\text { tre y cola blancos, hombros negros, alas } \\
\text { puntiagudas. }\end{array}$ \\
\hline
\end{tabular}




\begin{tabular}{|c|c|c|}
\hline orden / especie & talla $(\mathrm{cm})$ & forma y color \\
\hline \multicolumn{3}{|l|}{ Psittaciformes } \\
\hline Guacamaya roja & $81-96$ & $\begin{array}{l}\text { cuerpo compacto con cabeza grande, } \\
\text { cuello corto; cola larga; cara desnuda } \\
\text { rosada; plumaje rojo escarlata, con di- } \\
\text { bujo en ala rojo, amarillo y azul; rabadi- } \\
\text { lla azul. }\end{array}$ \\
\hline Loro frente blanca & $25.5-29$ & $\begin{array}{l}\text { frente blanca, corona azulada; plumaje } \\
\text { verdeamarillento. }\end{array}$ \\
\hline Loro yucateco & $25.5-28$ & $\begin{array}{l}\text { frente blanca; plumaje verde, mancha } \\
\text { roja en alas. }\end{array}$ \\
\hline \multicolumn{3}{|l|}{ Apodiformes } \\
\hline Ermitaño enano & $9-10$ & $\begin{array}{l}\text { arriba castaño con brillo bronceado; } \\
\text { abajo canela amarillento; pico curvo. }\end{array}$ \\
\hline Esmeralda tijera & $8.5-9$ & $\begin{array}{l}\text { O corona dorada; cuerpo verde azulado } \\
\text { metálico muy brillante, cola ahorquilla- } \\
\text { da. }\end{array}$ \\
\hline \multicolumn{3}{|l|}{ Coraciiformes } \\
\hline Martín pescador & $19-21$ & $\begin{array}{l}\text { cabeza grande, pico recto como daga; } \\
\text { verde aceitoso oscuro arriba, con collar } \\
\text { blanco y banda castaña en pecho; man- } \\
\text { chitas blancas en alas y cola. }\end{array}$ \\
\hline \multicolumn{3}{|l|}{ Passeriformes } \\
\hline $\begin{array}{l}\text { Clorofonia } \\
\text { Corona azul }\end{array}$ & $12-13.5$ & $\begin{array}{l}\text { verde perico con pico truncado; vientre } \\
\text { amarillo claro; medio collar y corona } \\
\text { azul turquesa. }\end{array}$ \\
\hline Picogordo azul & $16.5-17.5$ & $\begin{array}{l}\text { O azul oscuro opaco con dos barras } \\
\text { café oscuras en ala; pico grueso. }\end{array}$ \\
\hline
\end{tabular}

El resultado de este análisis comparativo determina que el tamaño de las diferentes especies no fue necesariamente un factor decisivo para la elección, ya que siete de ellas quedan dentro del intervalo que corresponde a la talla pequeña y otras seis poseen una talla que va de mediana grande a grande, por lo que existe un equilibrio, aún cuando el rango pueda considerarse amplio y encontrar un pequeño colibrí y un pelícano o un águila pescadora en la pintura mural.

Con relación a ciertas características físicas distintivas se observó que 12 de las 16 especies $(75 \%)$ presentan en alguna zona del cuerpo plumaje blanco 
(cuadro 5) en la frente o en el rostro plumas marginadas de blanco (como los loros y el cormorán); en el cuello una raya o lista lateral blanca (pelícano y garza); manchas blanquizcas en las alas o en la cola (anhinga, zopilote, pijije, martín pescador); el blanco se presenta en la cabeza, en pecho, vientre o en el dorso (la espátula rosada, águila pescadora y el milano).

Por otra parte, siete de 16 especies poseen el cuello y el pico largo en proporción con el cuerpo y las otras especies lo tienen más bien corto, fuerte y ganchudo, como se observa en los loros o el semillero Picogordo azul (Guiraca caerulea).

En consecuencia, se deduce que la presencia de plumas blancas en alguna región particular del cuerpo y el tamaño del cuello y pico sí pudieron ser factores determinantes en la elección de una especie.

CuAdro 6

HÁBITAT Y ALIMENTACIÓN DE LAS ESPECIES ESTUDIADAS

orden / especie

hábitat y hábitos alimenticios

Pelecaniformes

Pelícano café

Cormorán oliváceo

Marina, costera. Peces y crustáceos

Zonas y lagunas costeras, lagos, ciénegas, pantanos, manglar, zonas. Peces, anfibios, crustáceos

Anhinga americana Lagos, ríos, pantanos, manglar. Peces, reptiles, especies acuática

\section{Ciconiiformes}

Garza morena

Espátula rosada

Zopilote negro

Anseriformes

Pijije

Lagos y lagunas costeras, ríos. Vedeadora; peces, ranas, insectos, crustáceos.

Zonas costeras. Vedeadora; peces pequeños, crustáceos, Insectos, sanguijuelas.

Ampliamente distribuido. Costas, orillas de bosque, campos abiertos, zonas pobladas. Hábitos carroñeros.

Charcas, resacas, ciénegas dulces. Plantas acuáticas, semillas, peces, moluscos, crustáceos, insectos.

Falconiformes

Águila pescadora

Costas marinas, ríos, lagos. Peces.

Milano cola blanca

Campos abiertos con árboles. Insectos y pequeños reptiles. 


\section{Psittaciformes}

Guacamaya roja

Loro frente blanca

Loro yucateco

\section{Apodiformes}

Ermitaño enano

Esmeralda tijera

\section{Coraciiformes}

Martín pescador

\section{Passeriformes}

Clorofonia corona azul

Pico gordo azul
Bosques de tierras bajas, arroyos. Fruta, nueces, semillas, brotes, néctar.

Campos secos, tierras boscosas abiertas, matorrales. Frutos, semillas, brotes.

Bosques de pino, deciduos, húmedos. Frutos, semillas.

Bosques de tierras bajas, sotobosque, ecotonos con matorrales. Néctar de flores, insectos, arañas. Claros de bosque, ecotono matorrales. Néctar, insectos, arañas.

Tierras bajas, arroyos, ríos, lagos, pantanos. Peces pequeños, renacuajos e insectos.

Montañas subtropicales, ecotonos de bosque. Insectos, frutas, pequeñas, bayas, néctar.

Campos de malezas y arbustos, sauces, vegetación densa en ríos. Semillas, insectos, frutos pequeños.

A estos rasgos distintivos se debe sumar el tipo de hábitat que frecuentan estas especies, así como su dieta básica. A este respecto se tiene que nueve de las 16 especies (56.25\%) están relacionadas con cuerpos de agua, esto es, más de la mitad son aves marinas o costeras, viven en lagos, ciénegas, pantanos, manglares, ríos, arroyos o en simples charcas, motivo por el cual consumen de manera preferente diferentes tipos de peces, crustáceos, anfibios, reptiles e insectos. En oposición, las otras siete especies son propias de lugares boscosos o de matorrales en donde pueden encontrar insectos, arañas, frutos, bayas, semillas y néctar (cuadro 6), es decir, se distinguen dos clases principales de hábitat.

De nueva cuenta se revela un balance entre dos tipos básicos de hábitat y los dos cuadros generales de preferencias alimenticias, mismos que pudieron ser decisivos o sugerentes en el proceso de selección de una especie de ave para su inclusión en el lenguaje pictórico.

La escena conocida como "Aldea maya a orillas del mar", que procede de Chichén Itzá, constituye una prueba de la importancia que se le otorgara al 
ambiente, porque en ella no sólo se reseñan de modo fiel diversas actividades humanas, sino que se muestra igualmente con detalle y, a mi juicio, también con curiosidad, la riqueza de recursos naturales provenientes del mar. Desde luego que las aves están presentes, pues en la parte central de la escena se aprecia la imagen de una Garza morena, pero aquí se exhibe la fase blanca de su plumaje.

Por otra parte, el peso que se le concedió al ambiente y a los hábitos alimenticios de las aves, bajo determinados juicios simbólicos, quedó registrado en el tocado que porta el personaje número 15 del muro sur en el Cuarto 3 de Bonampak. En él se observa una cabeza de garza en cuyo pico largo, recto y agudo como lanza, se distingue prendido un anfibio anuro en un estado de metamorfosis (Navarijo, 2001) (figura 1).

El motivo de garza con un pez fue pintado en la cerámica clásica y forma parte del signo cuatripartita en los tocados, el cual se ha identificado con Itzamná, por lo que la garza pudo estar ligada a esa deidad celeste. De igual forma, este motivo se encuentra en paneles y relieves, o bien aparece en los códices, como el de Dresde, en donde a la relación garza/pez se le confirió un sentido de abundancia, y sí bien aquí la garza sujeta un anfibio y no una variedad de pez, estimo que se trata de una sustitución en la representación, pero

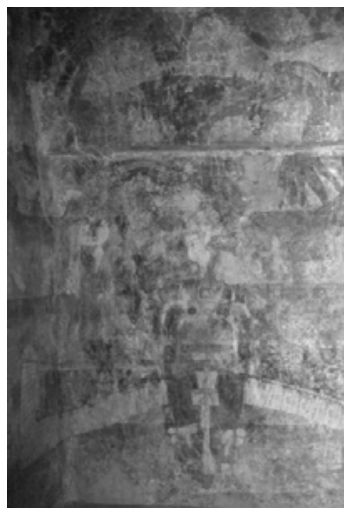

Figura 1. El personaje número 15 situado en el muro sur del Cuarto 3 en Bonampak, Chiapas, porta un gran tocado en el que se observa una cabeza de garza en cuyo pico se distingue prendido un anfibio (foto: Eduardo A. Cerezo) 
conservando el mismo mensaje simbólico de abundancia y tal vez de fertilidad. Para comprender este elemento simbólico, habrá que tener presente las preferencias de las garzas por los cuerpos de agua en donde se desarrollan muchos organismos, lo que en términos generales justifica este vínculo con la abundancia y, por extensión, con la vida misma (Navarijo, op. cit.).

La asociación de las garzas con el agua también se ve fortalecida al revisar lo que comenta Thompson (1975: 309) sobre los chaques. El autor nos dice que una denominación general para todos ellos es Ah Hoyaob, que significa "los que riegan" o "los que orinan", y al respecto señala que en el Códice Madrid se aprecia que la lluvia cae de entre las piernas de un Chac o una diosa, la O; pero en el Códice de Dresde, un Chac esta haciendo aguas y la orina acaba en la cabeza de una garza.

Los chaques como dioses de la lluvia estuvieron asociados a los relámpagos, truenos y rayos, asimismo fueron vinculados con los cuatro rumbos y con un color en particular. Se sabe por Landa (1973) que entre estos rumbos, al Norte le correspondía el blanco, y si como un ejercicio hipotético vemos un relámpago como una "raya", una "lista" o una especie de "franja" luminosa alba que se dibuja momentáneamente en el espacio celeste, así entonces pudieran entenderse o equipararse estos eventos naturales con un simple trazo blanco, tal vez como la banda o lista lateral blanca que presentan en la región del cuello la Garza morena y el Pelícano café y considerar, de esta forma figurada, a las aves relacionadas con el agua y a la vez con los dioses.

\section{Cometido simbólico}

Para ahondar en la propuesta de la existencia de patrones de selección que fueron conjugados con un posible papel simbólico, se presenta el caso de las cinco especies de aves que figuran en la pintura de Xuelén (cuadro 1), por considerar que su presencia confirma la hipótesis. Esta afirmación se apoya en los siguientes argumentos:

1) Priva el hecho de que en la expresión pictórica de Xuelén figuran cuatro especies de aves que cohabitan en condiciones naturales y que poseen una estrecha relación con el agua, debido principalmente a sus hábitos alimenticios. Aunada a esta circunstancia, cabe apuntar que para los mayas el agua terrestre de ríos, lagunas y mares no es distinta del agua de lluvia, más bien ésta procede de aquella porque siempre está en continuo movimiento, lo cual significa que el agua terrestre es la que asciende y el agua celeste es aquella que desciende, pero ambas son de naturaleza serpentina. Esta condición del agua es la que puede haber sido representada en Xuelen por medio del Pelícano café, el Cormorán oliváceo, la Anhinga americana, el Águila pescadora y de cierta forma a través del Zopilote negro. 
2) Al mismo tiempo, fue importante la experiencia adquirida sobre la utilidad de las aves como indicadoras de los fenómenos climáticos, tales como la llegada de las lluvias (agua finalmente), o bien del arribo o presencia de otras especies de valor alimenticio, pero también,

3) Es sugestivo advertir que las aves representadas ostentan tonalidades de rojizas a naranja y amarillo. Sin embargo, las especies determinadas biológicamente poseen plumajes oscuros que van desde el negro lustroso de la esbelta anhinga pasando por el negro-grisáceo del cormorán o bien el negro opaco sucio del zopilote, hasta el café oscuro del dorso del Águila pescadora y el café oscuro a grisáceo del Pelícano café. Además, al parecer, todas dirigen sus movimientos hacia la derecha, orientación que corresponde al poniente, que es el punto donde se encuentra el mar, lo que resulta consecuente ya que las aves en este caso pueden estar representando al Sol del ocaso, porque el negro era el color asignado al Oeste y sin embargo tenemos que al atardecer, cuando el Sol se va ocultando, el cielo se viste de colores rojizos.

Este acontecimiento brinda la pauta para comprender la elección de determinadas aves de plumaje oscuro, pero íntimamente relacionadas con el agua, así como su representación sustituyendo sus colores oscuros originales para lucir aquellos que estuvieran acordes con el crepúsculo.

4) Por último, habrá que considerar que se presenta el hecho de contar con una representación de la Luna, que es un cuerpo celeste que emite luz blanca brillante y por ello es el más conspicuo en la noche, y que estuvo vinculada a las aguas subterráneas, lagos y fuentes.

La suma de estos fundamentos expresa la confluencia de varias asociaciones muy interesantes, puesto que las aves están representando al Sol del ocaso y se relacionan al mismo tiempo con el agua, la que a su vez lo está con la Luna. Además, la Luna de igual forma se enlazó con determinadas cosmovisiones y en particular lo estuvo con el zopilote, el cual se vinculaba con el sacrificio, siendo una de las aves representadas en Xuelén.

\section{Conclusiones}

El alto grado de importancia que tuvieron las aves en la cosmovisión maya se confirma mediante las 28 especies registradas como individuos, o a través de sus plumas, en las diferentes muestras de pintura mural estudiadas.

Por otra parte, de acuerdo con el análisis expuesto, considero que, aun cuando se trata de especies que poseen tallas diferentes, estas aves comparten determinadas características físicas, como lo es la presencia de plumas blancas en alguna zona del cuerpo. Además, en este conjunto de especies se observa que coinciden la composición de su dieta y el hábitat que frecuentan, hechos físicos 
y conductuales que facultan pensar en la existencia de patrones o códigos de selección de las especies de aves para su inserción en el lenguaje pictórico, cargado de simbolismos tras la valoración de la naturaleza.

\section{BIBLIOGRAFÍA}

Barrera Vázquez, Alfredo

1992 Libro de los Cantares de Dzitbalché, 342-388, 2a ed., M. De la Garza, (comp.). Venezuela: Biblioteca Ayacucho (Colección Literatura Maya).

De la Garza, Mercedes

1995 Aves sagradas de los mayas. México: UNAM, IIFL, Centro de Estudios Mayas.

Flores-Villela, O. y P. Gerez

1988 Conservación en México: síntesis sobre vertebrados terrestres, vegetación y uso del suelo. México: Instituto Nacional de Investigaciones sobre Recursos Bióticos. Conservación Internacional.

Howell, S. N. y S. Webb

1995 A Guide to the Birds of Mexico and Northern Central America. Nueva York: Oxford University Press.

Landa, Diego

1973 Relación de las cosas de Yucatán. México: Editorial Porrúa (Biblioteca Porrúa, 13).

Navarijo Ornelas, María de Lourdes

1998 "Plumas... tocados: una vieja historia de identidades perdidas", en La pintura mural prehispánica en México, vol. 2, t. I, Estudios, pp. 177-191, B. De la Fuente (dir.), L. Staines (coord.). México: UNAM, Instituto de Investigaciones Estéticas.

1999 Análisis de representación faunística en una muestra de vasijas mayas del Clásico. Suplemento del Seminario Permanente de Iconografía (2): 1-19. México: Dirección de Etnología y Antropología Social e INAH.

2000 "Arte y ciencia a través de las imágenes de aves en la pintura mural prehispánica”, Anales XXII (77): 5 -32. México: UNAM, Instituto de Investigaciones Estéticas.

2001 "Las aves en el mundo maya prehispánico", en La pintura mural prehispánica en México, vol. 2, t. III, Área Maya, Estudios, pp. 221-253, B. De la Fuente (dir), L. Staines (coord.). México: UNAM, Instituto de Investigaciones Estéticas. 
Peterson, R. T. y E. L. Chalif

1989 Aves de México. Guía de Campo. México: Diana.

Popol Vuh. Antiguas leyendas del Quiché

1985 Versión de E. Abreu, G. E. México: Ediciones Oasis (Colección Los Esenciales, 1).

Thompson, J. Eric S.

1975 Historia y religión de los mayas. México: Siglo XXI. 